\title{
Écrire le sable
}

Writing Sand

\section{Frédéric Joulian et Pierre-Olivier Dittmar}

\section{(2) OpenEdition}

Journals

Édition électronique

URL : https://journals.openedition.org/tc/7191

DOI : $10.4000 /$ tc. 7191

ISSN : 1952-420X

\section{Éditeur}

Éditions de l'EHESS

\section{Édition imprimée}

Date de publication : 15 décembre 2013

Pagination : 4-7

ISBN : 978-2-7351-1654-6

ISSN : 0248-6016

\section{Référence électronique}

Frédéric Joulian et Pierre-Olivier Dittmar, «Écrire le sable », Techniques \& Culture [En ligne], 61 | 2013, mis en ligne le 15 mai 2014, consulté le 29 septembre 2022. URL : http://journals.openedition.org/tc/ 7191 ; DOI : https://doi.org/10.4000/tc.7191 


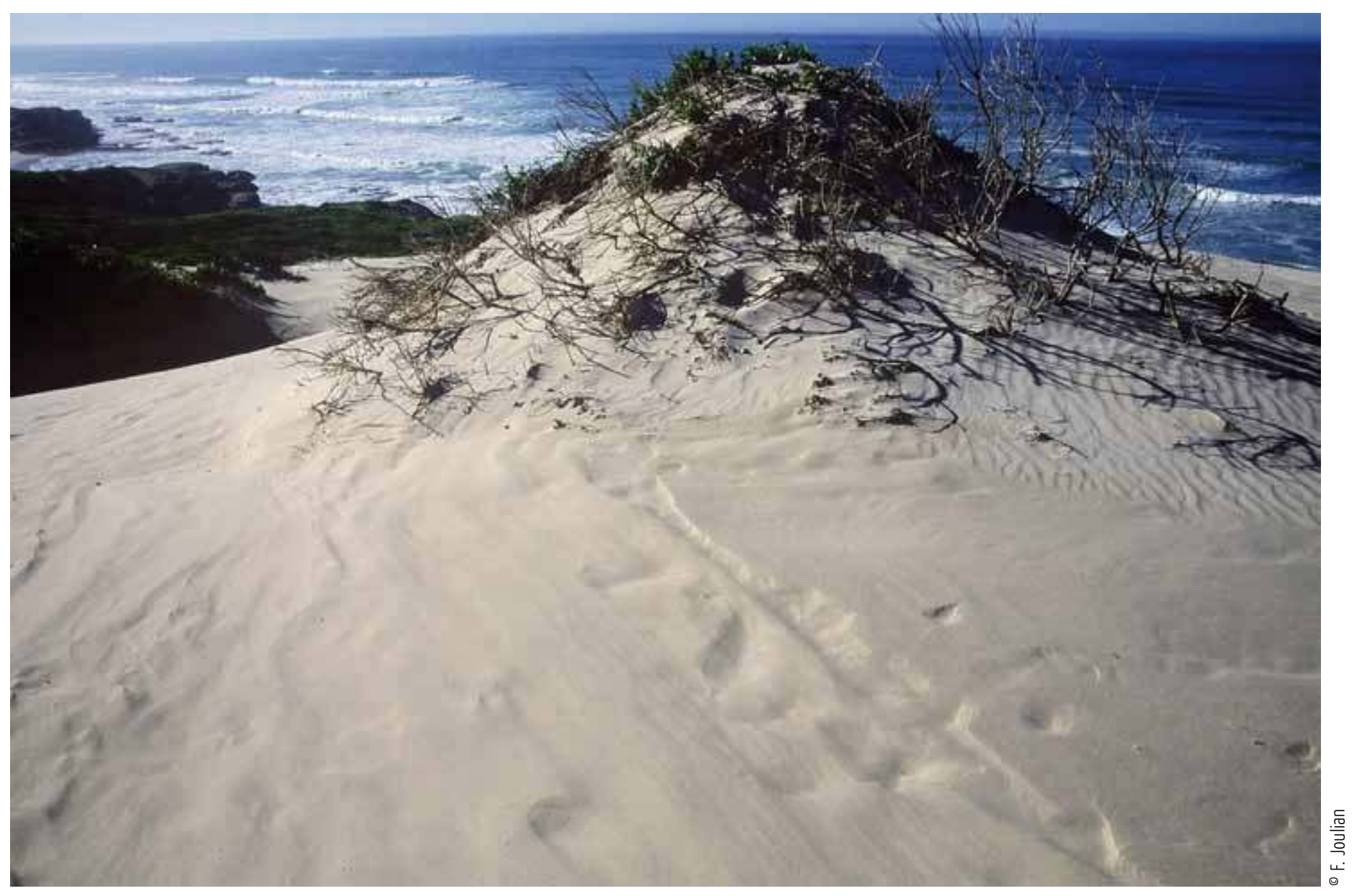




\section{Frédéric Joulian}

Pierre-Olivier Dittmar

Techniques \& Culture 61, 2013/2: 4-7

\section{EHESS}

Frederic.Joulian@ehess.fr

pierre-olivier.dittmar@ehess.fr

\section{ÉCRIRE LE SABLE}

Le lecteur régulier de TechniquesÉculture sera peut-être surpris de l'utilisation enthousiaste du titre, du type de ceux qu'utilisaient les voyagistes et les clubs de vacances dans les années 80, mais telle était notre envie de secouer ce dernier numéro de la revue réalisé avec les éditions de la FMSH ; de bousculer un peu aussi l'imagerie romantique attachée au désert, réintroduisant les hommes, les dimensions vécues et la modernité dans ce numéro à voix multiples. L'ethnologie d'abord, mais aussi la physique, la géographie, la zoologie, la linguistique ou l'archéologie explorent différentes facettes des modes de vie associées aux milieux sableux, dont les états, solide ou fluide, invitent soit à la paresse, soit à la réflexion.

Le sable, comme l'eau, s'immisce sous les toiles ou les portes, il « chante » dans les dunes, offre mille ressources en même temps que contraintes, et tantôt efface, tantôt enregistre les passages et signes d'activités des usagers sahariens, arabes ou australiens que convoque ce numéro coordonné par deux spécialistes de l’Afrique saharienne, Sébastien Boulay et Marie-Luce Gélard. Les deux coordonnateurs mêlent les modes de vie traditionnels et la modernité des sociétés confrontées à ce milieu granulaire.

Choisir d'aborder les questions sociales et techniques à partir d'une matière et de ses effets pratiques sur les modes de vie, sur les émotions ou conceptualisations ; révéler les liens entre un substrat, ses usages et ses représentations, constitue une sorte de pari que nous vous livrons aujourd'hui comme un objet inédit d'exploration. Le sable, épiderme sensible sur lequel on déambule en divers endroits du monde, sur lequel écrire et lire en même temps, invite à l'exactitude, à des temporalités précises et offre désormais un champ immense où comprendre différemment les rapports humains au temps — dans des écritures à vivre. 


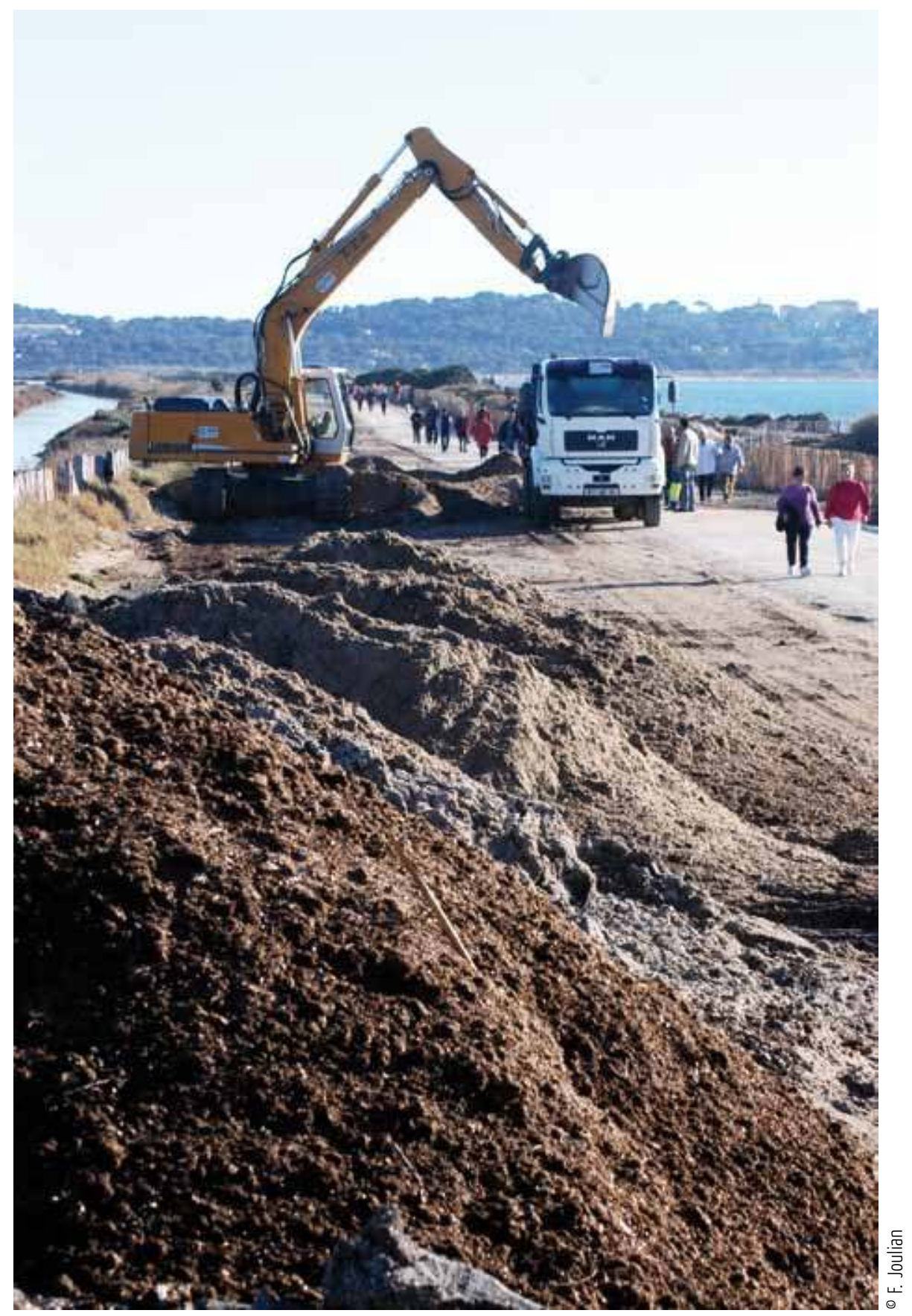

Les sables littoraux utilisés pour les constructions bétonnées de plus en plus nombreuses tout autour de la planète deviennent, à l'instar du pétrole ou de l'eau, des ressources rares qui posent de véritables problèmes écologiques et économiques. Ici, désensablement d'un cordon littoral où l'on peut observer, au gré des tempêtes, que l'érosion et l'ensablement peuvent aller de pair, devenir le lieu de travaux sans fin, de controverses environnementales comme de promenades badines. Almanarre, Var 2007 
De numéro en numéro, les articles publiés en Varia continuent d'illustrer la diversité et le dynamisme des études sur les techniques et les objets. Le premier, de Giulia Anichini, est issu d'un travail d'anthropologie des sciences. Il interroge la place du bricolage dans les activités de recherche en neuroimagerie cérébrale. Il démontre, s'il le fallait encore, l'intrication compliquée des innovations techniques et des protocoles scientifiques tout autant que les frictions parfois fortes entre la technique et la recherche. Le second Varia, proposé par un économiste, Gérard Marty, décrit de façon détaillée la question du commerce du bois à travers une socio-pragmatique des enchères publiques, théâtre révélateur d'un secteur où les usages sont bouleversés par d'importantes mutations. « Les grandes gueules » film emblématique de la France rurale des années 60, illustre magnifiquement ce sujet. Nous remercions les ayants-droit pour la reproduction des photogrammes.

Un article du géographe Augustin Berque nous permet finalement de renouer avec un thème fondateur de l'anthropologie, celui de «technique du corps », qu'il aborde à propos de la marche au Japon. Cela nous donne l'occasion de redire l'importance des regards croisés et intégrés (philosophie, géographie, histoire, anthropologie dans son cas) sur cet objet total!

Trois Curiosa complètent l'ensemble, les deux premiers sont relatifs au Thema sur le sable (un récit photographique de géographes à propos des villes d'Arabie-Saoudite) et une interview d'un archéologue saharien ; le troisième est le récit graphique innovant d'une jeune ethnologue, Lucie Smolderen et d'un dessinateur, Romain Minguet, qui retracent l'histoire d'une technique disparue, le tissage dans le Nord du Bénin, restituée par l'écrit, le dessin et la photographie. Cet essai graphique en bande dessinée constitue une étape dans une réflexion plus globale menée par TechniquesÉculture sur les différentes possibilités de narration alternative des sciences humaines. Il s'agit dans chacun des cas, non seulement de proposer une présentation stimulante pour un public non spécialiste, mais surtout de trouver la forme la plus pertinente, au-delà des habitudes confortables que propose le canon de l'article académique, pour traduire au plus juste la parole des acteurs et l'expérience de terrain.

Telle est, plus globalement l'orientation que nous souhaitons donner à la revue qui avec les éditions de l'EHESS en 2015 explorera une nouvelle formule en ligne à usage savant et sur papier à usage plus généraliste.

Photo d'ouverture: Parc naturel De Hoop, Afrique du Sud 2003. (Cl. F. Joulian) 